\title{
Association of acute kidney injury with readmissions after hospitalization for acute exacerbation of chronic obstructive pulmonary disease: A population-based study
}

\author{
Atsushi Hirayama ( $\square$ ath877@mail.harvard.edu ) \\ Osaka University https://orcid.org/0000-0002-6712-6930 \\ Tadahiro Goto \\ Massachusetts General Hospital \\ Kohei Hasegawa \\ Massachusetts General Hospital
}

\section{Research article}

Keywords: acute exacerbation of COPD, acute kidney injury, readmission, population-based study

Posted Date: March 24th, 2020

DOI: https://doi.org/10.21203/rs.2.17872/v4

License: (c) (i) This work is licensed under a Creative Commons Attribution 4.0 International License.

Read Full License

Version of Record: A version of this preprint was published at BMC Nephrology on April 3rd, 2020. See the published version at https://doi.org/10.1186/s12882-020-01780-2. 


\section{Abstract}

Background and Aim : Little is known about the relationship between acute kidney injury (AKI) and outcomes after acute exacerbation of chronic obstructive pulmonary disease (AECOPD). We aimed to investigate associations between AKI and readmission risks after hospitalization for AECOPD.

Methods : A retrospective, population-based cohort study using State Inpatient Databases from seven U.S. states (Arkansas, California, Florida, lowa, Nebraska, New York, and Utah) from 2010 through 2013. We identified all adults (aged $\geq 40$ years) hospitalized for AECOPD during the study period. Among them, we further identified patients with a concurrent diagnosis of new AKI. The outcome measures were anycause readmissions within 30 days and 90 days after hospitalization for AECOPD. To determine associations between AKI and readmission risk, we constructed Cox proportional hazards models examining the time-to-readmission. We also identified the primary reason of readmission.

Results: We identified 356,990 patients hospitalized for AECOPD. The median age was 71 years and $41.9 \%$ were male. Of these, $24,833(7.0 \%)$ had a concurrent diagnosis of AKI. Overall, patients with AKI had significantly higher risk of 30-day all-cause readmission compared to those without AKI (hazard ratio $1.47 ; 95 \% \mathrm{Cl} 1.43-1.51 ; \mathrm{P}<0.001)$. Likewise, patients with AKI had significantly higher risk of 90-day allcause readmission (hazard ratio $1.35 ; 95 \% \mathrm{Cl} 1.32-1.38 ; \mathrm{P}<0.001$ ). These associations remained significant after adjustment for confounders (both $\mathrm{P}<0.05$ ). Additionally, patients with AKI were likely to be readmitted for non-respiratory reasons including sepsis, acute renal failure, and congestive heart failure.

Conclusions : Among patients hospitalized for AECOPD, patients with AKI were at higher risk of 30-day and 90-day readmission, particularly with non-respiratory reasons.

\section{Background}

Acute exacerbation of chronic obstructive pulmonary disease (AECOPD) is a major public health burden accounting for 600,000 hospitalizations in the US annually [1]. As a readmission after hospitalization for AECOPD is a common and costly event [2,3], investigating its characteristics and risks are important. Acute kidney injury (AKI) is another important public health burden; the incidence of AKI has been reported to be $5 \%$ of hospitalized patients and $30 \%$ of critically ill patients [4]. These two acute conditions share similar pathobiology in the development and progression, such as systemic inflammation [5].

The literature has reported relationships between these two conditions. For example, according a study using clinical database of the United Kingdom, the incidence and prevalence of AKI were higher in patients with COPD compared to those reported in previous studies in general populations and hospitalizations [6]. Additionally, cross-sectional studies have also reported that patients hospitalized for AECOPD with AKI had higher in-hospital mortality, compared to those without AKI [6, 7]. Despite the clinical importance, no longitudinal study has investigated whether AKI is associated with the subsequent 
risk of readmissions in patients hospitalized for AECOPD-a population with large morbidity burden and healthcare use.

To address this knowledge gap, we aimed to investigate the association of AKI with all-cause readmissions within 30 and 90 days after hospitalization for AECOPD.

\section{Methods}

\section{Study Design and Setting}

We conducted a retrospective cohort study using large, population-based data from the Healthcare Cost and Utilization Project (HCUP) State Inpatient Database (SID) of seven geographically-dispersed US states (Arkansas, California, Florida, lowa, Nebraska, New York, and Utah) from 2010 through 2013. The HCUP is a family of healthcare databases that are developed through a federal-state-industry partnership and sponsored by the Agency for Healthcare Research and Quality (AHRQ). The HCUP is the largest collection of longitudinal hospital care data in the US, with all-payer, encounter-level information. The HCUP SIDs capture al/ hospitalizations, regardless of source of disposition, from acute care, non-federal, general and other specialty hospitals within the participating states [8]. These seven states were selected for their high data quality, geographic distribution, and mainly because their data included unique encrypted patient identifiers that enable longitudinal follow-up of specific individuals across years (including identification of readmissions). The institutional review board of Massachusetts General Hospital approved this study.

\section{Study Population}

We identified all hospitalized adult patients (aged $>40$ years) with a principal discharge diagnosis of COPD, as defined by the International Classification of Diseases, Ninth Revision, Clinical Modification (ICD-9-CM) diagnosis codes of 491.21, 491.22, 491.8, 491.9, 492.8, 493.20, 493.21, 493.22, and 496, or those with a primary diagnosis of respiratory failure (codes 518.81, 518.82, 518.84, and 799.1) and a secondary diagnosis of COPD $[9,10]$. In the current analysis, we used only the first hospitalizations of the eligible patients during the study period. We also excluded patients who left the hospital against medical advice, those who died in-hospital at their index hospitalization, those who were transferred to another acute-care facility, and out-of-state residents.

\section{Measurements}

The SID contain information on the patient characteristics, including demographics (age, sex, and race/ethnicity), primary insurance type (payer), quartiles for estimated household income, patient residence, ICD-9-CM diagnosis and procedure codes, patient comorbidities (29 Elixhauser comorbidity 
measures and arrhythmia), hospital course (e.g., hospital length-of-stay, in-hospital death), and disposition.

\section{Primary Exposure}

The primary exposure was the development of in-hospital AKI during the index hospitalization for AECOPD, as defined by the ICD-9-CM diagnostic codes of 584.5, 584.6, 584.7, 584.8, and 584.9 in any diagnostic fields $[11,12,13]$, with excluding AKI as an admission diagnosis. Additionally, we also identified AKI with the use of dialysis, defined as having both of AKI (diagnostic codes, 584.5-584.9) and hemodialysis (procedure code of 39.95 or diagnostic code of V45.1, V56.0 or V56.1) [11, 12].

\section{Outcome Measures}

The outcome measures were readmission attributable to any cause within 30 and 90 days of discharge from the index hospitalization for AECOPD. In the COPD literature, 30-day readmission rates have been investigated $[9,13,14]$ in the context of the Centers for Medicare and Medicaid Services'Hospital Readmissions Reduction Program (HRRP) [15]; 90-day readmission rates have also been recognized as an important clinical indicator $[16,17]$. The secondary outcome measure was the primary discharge diagnosis of the readmission. To make data presentation and interpretation more meaningful, we consolidated the principal discharge diagnoses (>14,000 ICD-9-CM diagnosis codes) into 285 mutually exclusive diagnostic categories by using the AHRQ-defined Clinical Classifications Software (CCS) [18].

\section{Statistical Analysis}

First, we compared the patient characteristics between patients with and without AKI by using Wilcoxon rank sum test or chi-squared test, as appropriate. We also compared Kaplan-Meier curves between the two groups with the use of the log-rank test. Next, we modeled the time-to-readmission by fitting Cox proportional hazards models with generalized estimating equations accounting for patient clustering within hospitals (e.g., severity of patients, physicians' preference in disease management within hospitals) $[19,20]$. The time-to-readmission for each patient was defined as the period from the discharge to when the first readmission occurred within the 30-day and 90-day follow-up periods. Patients who did not have an outcome were censored at 30 days (or 90 days) from discharge or in-hospital death during the corresponding follow-up period, whichever occurred first. We fitted Cox proportional hazards model with adjustment for potential confounders, such as age, sex, race/ethnicity, primary insurance, quartiles for median household income, residential status, length-of-stay at the index hospitalization, hospital state, and 28 Elixhauser comorbidities as well as arrhythmia [21, 22]. Furthermore, as sensitivity analyses, we repeated the analysis with stratifications by age category (40-64 years and $\geq 65$ years) and sex as 
previous studies have reported age- and sex-related differences in the readmission rate after hospitalization for AECOPD $[9,13,14]$. Additionally, we repeated the analysis with stratifications by presence of renal failure (or chronic kidney disease [CKD]) indicated in the Elixhauser comorbidities. Lastly, we compared the 30-day and 90-day readmission rates and calculated the unadjusted and adjusted hazard ratios among patients without AKI, those with AKI without dialysis use, and healthcare use and with $\mathrm{AKI}$ and dialysis use. We primarily conducted an available case analysis, and examined consistency with the results of complete case analysis. All analyses used STATA 14.0 (STATA Corp, College Station, TX). All P values were two-tailed, with $\mathrm{P}<0.05$ considered statistically significant.

\section{Results}

We first identified 385,604 patients hospitalized for AECOPD in the seven U.S. states. From these, we excluded 6,911 patients who left the hospital against medical advice, 5,613 patients who died in-hospital at the index hospitalization, 4,378 patients who were transferred to another acute-care facility, and 11,712 out-of-state residents. Finally, a total of 356,990 patients were eligible for the present analysis (Supplemental Figure 1). Overall, the median age was 71 years, $41.9 \%$ were male, and $73.9 \%$ were nonHispanic white; $7.0 \%$ had a new diagnosis of AKI during the index hospitalization. The patient characteristics differed between patients with AKI and those without AKI (Table 1)-for example, the AKI group was more likely to be older and male. Overall, 58,076 (16.3\%) patients had at least one readmission within 30 days after their index hospitalization, and 112,917 (31.6\%) had at least one readmission within 90 days after their hospitalization. (Supplemental Table 1).

The Kaplan-Meier survival curves demonstrated a significant difference in the risk of all-cause 30-day and 90-day readmission between patients with AKI and those without AKI $(P<0.001$, Figures 1 and 2). In the unadjusted Cox proportional hazards model, patients with AKI had a significantly higher risk of 30-day readmission when compared to those without AKI (hazard ratio $[\mathrm{HR}] 1.47 ; 95 \% \mathrm{Cl} 1.43-1.51 ; \mathrm{P}<0.001$; Table 2). In the adjusted model, the significant association persisted (HR 1.07; 95\% Cl 1.04-1.11; $\mathrm{P}<0.001$ ). Likewise, with regard to all-cause 90 -day readmission, patients with AKI had a significantly higher risk of 90-day readmission (HR 1.35; 95\% Cl 1.32-1.38; $\mathrm{P}<0.001$; Table 3 ). The significant association also persisted after adjustment for potential confounders (HR 1.03; 95\% Cl 1.00-1.05; $\mathrm{P}=0.04$ ). With stratifications by age, sex and presence of CKD indicated in the Elixhauser comorbidities, these associations remained significant in patients aged $\geq 65$ years, women, and patients without CKD (all $P<0.05$, Tables 2 and 3 ). There was a statistically significant interaction between AKI and the presence of CKD on the risks of 30-day and 90-day readmission after hospitalization for AECOPD (both $P_{\text {interaction }}<0.05$ ). The complete case analyses also showed consistent results (Supplemental Tables 2-4). In the stratified analysis by dialysis use, both AKI groups had higher 30-day and 90-day readmission rates, compared with those without AKI (unadjusted $\mathrm{P}<0.001$; Supplemental Table 5). Despite the limited statistical power in this stratified analysis, the association between AKI and higher 30-day readmission rate remained significant after adjustment in the AKI without hemodialysis group. 
Among patients without AKI, the most frequent primary cause for 30-day readmission was COPD, followed by pneumonia, respiratory failure, and asthma; Table 4). By contrast, patients with AKI were more likely to be readmitted due to non-respiratory diseases (e.g., sepsis, acute renal failure, congestive heart failure). The five most frequent causes of readmission were not different between 30-day and 90day readmissions after hospitalization for AECOPD (Table 4 and Supplemental Table 6).

\section{Discussion}

In this large population-based study of 356,990 patients hospitalized for AECOPD in the seven U.S. states, we found that patients with AKI had a $50 \%$ higher risk of all-cause readmissions during 30 days after their index hospitalization when compared to those without AKI. This significant association persisted after the adjustment for potential confounders. The limited epidemiological literature has indicated the association of acute kidney disease with COPD [23]. For example, a retrospective cohort study using electronic medical records in Taiwan showed that COPD is associated with a higher risk of development of AKI [23]. Furthermore, among patients hospitalized for AECOPD, those with AKI had approximately 2fold higher mortality rate within six months compared to those without AKI [6]. Our findings based on the large population-based data corroborate these prior studies, and extend them by demonstrating the longitudinal association of AKI with a higher risk of all-cause readmission after hospitalization for AECOPD.

The underlying mechanisms of the observed association of AKI with higher risks of readmission after hospitalization for AECOPD warrant clarification. In the present study, part of the association was attributable to the differences in patient-level socio-demographic factors, hospital length-of-stay and comorbidities between the two target populations. However, despite the rigorous adjustment, AKI remained an independent risk factor for readmission in patients hospitalized for AECOPD. This finding suggests that there are other factors predisposing patients with AKI to worse clinical outcomes. One potential mechanism is impaired immunity following AKI $[24,25]$. Indeed, studies have showed that AKI is a risk factor for subsequent infection (e.g., incident active tuberculosis infection [26] and sepsis [27]). Consistently, we observed that the most frequent primary cause of readmission was sepsis in the patients with AKI, while the most common cause was COPD in those without AKI. Furthermore, AKI-related systemic inflammation [5] and volume overload [28] may add to the existent morbidity in patients hospitalized for AECOPD. These potential mechanisms may have independently or jointly contributed to worse disease control of COPD, exacerbation of existent comorbidities, and increased disease susceptibility, thereby leading to greater healthcare utilization in patients with concurrent AECOPD and AKI. Additionally, we also observed the age- and sex-related difference in the association of AKI with readmission risks after hospitalization for AECOPD. Consistently, previous epidemiologic studies have also indicated the age and sex-related difference in severity of AKI, morbidity and mortality after AKI in other disease populations $[6,12,29,30,31,32,33]$. These data collectively suggest the interplay between the patient biological characteristics (age, sex), AKI, and AECOPD, and their integrated contributions to subsequent morbidity risk, which merits further investigations. 
Our study has several potential limitations. First, in this large population-based study, detailed information on renal function was unavailable. Yet, adjusting for the Elixhauser comorbidities should have accounted, at least partially, for potential confounding by this factor. Additionally, to account for the potential effect of AKI severity, we also performed the sensitivity analysis stratified by use of dialysis. Second, as we used administrative datasets, there may be misclassifications, such as misdiagnosis of AECOPD and AKI. Nevertheless, the ICD-9-CM codes for COPD are widely used [8, 9], and the HCUP data are rigorously tested and considered accurate $[13,34,35,36]$. Additionally, while the literature showed that the ICD-9-CM codes for AKI had a high specificity and low sensitivity [37], underdiagnoses or misclassifications of AKI at the index hospitalization are likely to have occurred equally regardless of the subsequent outcomes, which would have biased our estimates toward the null. Third, SIDs do not capture information on out-of-hospital deaths, which precluded us from accounting for this potential competing risk. In contrast, we accounted for the potential effect of in-hospital deaths during the follow-up periods. Fourth, as with any observational study, the causal inference of AKI with readmission risks might be confounded by unmeasured factors (e.g., access to ambulatory healthcare, patient's health behavior). Lastly, the studied data are not a random sample of all individuals with AECOPD in the U.S. However, the seven geographically-dispersed states represent approximately $27 \%$ of the U.S. population, thereby supporting the generalizability of our inferences.

\section{Conclusions}

In the large population-based database of 356,990 patients hospitalized for AECOPD across seven US states, we found that patients with AKI had a significantly higher risk of all-cause readmissions during 30 and 90 days after their index hospitalization, compared to those without AKI. For clinicians, our findings underscore the importance of prevention of AKI and post-discharge care in this population. For researchers, our findings should facilitate further investigations into the mechanisms underlying the COPD-AKI link to develop preventive and therapeutic interventions in this population with large morbidity burden and healthcare use.

\section{Abbreviations}

AECOPD: acute exacerbation of chronic obstructive pulmonary disease

AHRQ: Agency for Healthcare Research and Quality

AKI: acute kidney injury

CKD: chronic kidney disease

COPD: chronic obstructive pulmonary disease

HCUP: Healthcare Cost and Utilization Project 
HRRP: Hospital Readmissions Reduction Program

ICD-9-CM: International Classification of Diseases, Ninth Revision, Clinical Modification

SID: State Inpatient Database

\section{Declarations}

\section{Ethical approval and consent to participate}

The institutional review board of Massachusetts General Hospital approved this study and the requirement for informed consent was waived.

\section{Consent for publication}

Not applicable

\section{Availability of data and materials}

HCUP's Nationwide and State-Specific Databases are available for purchase from the online HCUP distributor (information available at: https://www.hcup-us.ahrq.gov/tech_assist/centdist.jsp).

\section{Competing interests}

The authors declare that they have no competing interests

\section{Funding}

This study was supported by the grant R01 HS023305 from the Agency for Healthcare Research and Quality (Rockville, MD, USA). Agency for Healthcare Research and Quality did not involve in the design of the study, analysis, interpretation of data and writing the manuscript. The content of this manuscript is solely the responsibility of the authors and does not necessarily represent the official views of the Agency for Healthcare Research and Quality.

\section{Authors' contributions}


$\mathrm{AH}, \mathrm{TG}$, and $\mathrm{KH}$ conceived the study. AH and TG analyzed the data. AH drafted the manuscript. $\mathrm{KH}$ supervised the conduct of the study. Finally, all authors contributed substantially to its revision and all authors had access to data.

\section{Acknowledgement}

Dr. Hirayama was supported by a grant from the Fulbright Scholarship.

\section{References}

1. HCUP net. Agency for Healthcare Research and Quality. http://hcupnet.ahrq.gov/.Accessed December 24, 2019.

2. Press VG, Konetzka RT, White SR. Insights about the economic impact of chronic obstructive pulmonary disease readmissions post implementation of the hospital readmission reduction program. Curr Oinion Pulm Med. 2018 Mar;24(2):138-146. doi: 10.1097/mcp.0000000000000454.

3. Mannino DM, Buist AS. Global burden of COPD: risk factors, prevalence, and future trends. Lancet. 2007 Sep 1;370(9589):765-73. doi: 10.1016/s0140-6736(07)61380-4.

4. Thadhani R, Pascual M, Bonventre JV. Acute renal failure. N Engl J Med. 1996 May 30;334(22):144860. doi: 10.1056/nejm199605303342207.

5. Rabb H, Griffin MD, McKay DB, et al. Inflammation in AKl: Current understanding, key questions, and knowledge gaps. J Am Soc Nephrol. 2016 Feb;27(2):371-9. doi: 10.1681/asn.2015030261.

6. Barakat MF, McDonald HI, Collier TJ, et al. Acute kidney injury in stable COPD and at exacerbation. Int J Chron Obstr Pulmon Dis. 2015;10:2067-77. doi: 10.2147/copd.s88759.

7. Cao CC, Chen DW, Li J, et al. Community-acquired versus hospital-acquired acute kidney injury in patients with acute exacerbation of COPD requiring hospitalization in China. Int J Chron Obstr Pulmon Dis. 2018 Jul 17;13:2183-2190.

8. Overview of the State Inpatient Database (SID). Healthcare cost and utilization project. https://www.hcup-us.ahrq.gov/sidoverview.jsp. Accessed December 24, 2019.

9. Goto T, Faridi MK, Gibo K, et al. Sex and racial/ethnic differences in the reason for 30-day readmission after COPD hospitalization. Respir Med. 2017 Oct;131:6-10. doi: 10.1016/j.rmed.2017.07.056.

10. Hasegawa K, Tsugawa Y, Tsai C-L, et al. Frequent utilization of the emergency department for acute exacerbation of chronic obstructive pulmonary disease. Respir Res. 2014;15(1):40.

11. Hsu RK, McCulloch CE, Dudley RA, et al. Temporal changes in incidence of dialysis-requiring AKI. J Am Soc Nephrol. 2013 Jan;24(1):37-42. doi: 10.1681/asn.2012080800.

12. Hsu RK, McCulloch $C E$, Heung $M$, et al. Exploring potential reasons for the temporal trend in dialysisrequiring AKI in the United States. Clin J Am Soc Nephrol. 2016 Jan 7;11(1):14-20. doi: 
$10.2215 /$ cjn.04520415.

13. Goto T, Faridi MK, Gibo K et al. Trends in 30-day readmission rates after COPD hospitalization, 20062012. Respir Med. 2017;130:92-97.

14. Ford ES. Hospital discharges, readmissions, and ED visits for COPD or bronchiectasis among US adults: findings from the nationwide inpatient sample 2001-2012 and Nationwide Emergency Department Sample 2006-2011. Chest. 2015;147:989-998.

15. Center for Medicare and Medicaid Services. Hospital Readmissions Reduction Program (HRRP). https://www.cms.gov/medicare/medicare-fee-for-service-payment/acuteinpatientpps/readmissionsreduction-program/. Accessed December 24, 2019.

16. Echevarria C, Steer J, Heslop-Marshall K, et al.. The PEARL score predicts 90-day readmission or death after hospitalisation for acute exacerbation of COPD. Thorax. 2017;72:686-693.

17. Sawhney S, Marks A, Fluck N,et al. Acute kidney injury as an independent risk factor for unplanned 90-day hospital readmissions. BMC Nephrol. 2017;18:9.

18. Blecker S, Paul M, Taksler G, et al. Heart failure-associated hospitalizations in the United States. $J$ Am Coll Cardiol. 2013;61(12):1259-1267.

19. Hirayama A, Goto T, Shimada YJ, et al. Association of obesity with severity of heart failure exacerbation: A population-based study. J Am Heart Assoc 2018;7.

20. Goto T, Hirayama A, Faridi MK, et al. Obesity and severity of acute exacerbation of chronic obstructive pulmonary disease. Ann Am Thorac Soc. 2018;15:184-191.

21. Elixhauser A, Steiner C, Harris DR, et al. Comorbidity measures for use with administrative data. Med Care. 1998;36(1):8-27.

22. Thompson NR, Fan Y, Dalton JE, et al. A new Elixhauser-based comorbidity summary measure to predict in-hospital mortality. Med Care. 2015;53(4):374.

23. Hsu CN, Lee CT, Su CH, et al. Incidence, outcomes, and risk factors of community-acquired and hospital-acquired acute kidney injury: A retrospective cohort study. Medicine. 2016 May;95(19):e3674. doi: 10.1097/md.0000000000003674.

24. Kluth DC, Erwig LP, Rees AJ. Multiple facets of macrophages in renal injury. Kidney Int. 2004 Aug;66(2):542-57. doi: 10.1111/j.1523-1755.2004.00773.x.

25. Doi K, Rabb H. Impact of acute kidney injury on distant organ function: recent findings and potential therapeutic targets. Kidney Int. 2016 Mar;89(3):555-64. doi: 10.1016/j.kint.2015.11.019.

26. Wu VC, Wang CY, Shiao CC, et al. Increased risk of active tuberculosis following acute kidney injury: a nationwide, population-based study. PloS One. 2013;8(7):e69556. doi:

10.1371/journal.pone.0069556.

27. Lai TS, Wang CY, Pan SC, et al. Risk of developing severe sepsis after acute kidney injury: a population-based cohort study. Crit Care. 2013 Oct 11;17(5):R231. doi: 10.1186/cc13054.

28. Prowle JR, Echeverri JE, Ligabo EV, et al. Fluid balance and acute kidney injury. Nat Rev Nephrol. 2010 Feb;6(2):107-15. doi: 10.1038/nrneph.2009.213. 
29. Siew ED, Parr SK, Abdel-Kader K,et al. Predictors of recurrent AKI. J Am Soc Nephrol. 2016;27:1190200.

30. Xue JL, Daniels F, Star RA, et al. Incidence and mortality of acute renal failure in Medicare beneficiaries, 1992 to 2001. J Am Soc Nephrol. 2006;17:1135-42.

31. Kumar AB, Suneja M. Cardiopulmonary bypass-associated acute kidney injury. Anesthesiology. 2011;114:964-70.

32. Thiele RH, Isbell JM, Rosner MH. AKI associated with cardiac surgery. Clin J Am Soc Nephrol. 2015;10:500-14.

33. Neugarten J, Sandilya S, Singh B, et al. Sex and the risk of AKI following cardio-thoracic surgery: A Meta-Analysis. Clin J Am Soc Nephrol 2016;11:2113-2122.

34. Walkey AJ, Wiener RS, Ghobrial JM, et al. Incident stroke and mortality associated with new-onset atrial fibrillation in patients hospitalized with severe sepsis. JAMA. 2011;306(20):2248-2254.

35. Davis JD, Olsen MA, Bommarito K, et al. All-Payer Analysis of Heart Failure Hospitalization 30-Day Readmission: Comorbidities Matter. Am J Med. 2017;130(1):93. e9-93. e28.

36. Storrow $A B$, Jenkins $C A$, Self $W H$, et al. The burden of acute heart failure on US emergency departments. JACC: Heart Fail. 2014;2(3):269-277.

37. Waikar SS, Wald R, Chertow GM, et al. Validity of International Classification of Diseases, Ninth Revision, Clinical Modification Codes for Acute Renal Failure. J Am Soc Nephrol. 2006 Jun;17(6):1688-94. doi: 10.1681/asn.2006010073.

\section{Supplemental File Legend}

\section{Supplemental Figure 1. Patient flow of the study}

AECOPD, acute exacerbation of chronic obstructive pulmonary disease

\section{Tables}

Table 1. Characteristics of patients hospitalized for acute exacerbation of chronic obstructive pulmonary disease by acute kidney injury 


\begin{tabular}{|c|c|c|c|}
\hline & $\begin{array}{c}\text { AKI } \\
\mathrm{n}=24,833\end{array}$ & $\begin{array}{c}\text { Non-AKI } \\
n=332,157\end{array}$ & $P$ value \\
\hline $\begin{array}{l}\text { Characteristics } \\
\text { Age (year), median (IQR) }\end{array}$ & $\frac{(7.0 \%)}{76(67-83)}$ & $\frac{(93.0 \%)}{70(60-80)}$ & $<0.001$ \\
\hline Male & $12,605(50.8)$ & $136,949(41.2)$ & $<0.001$ \\
\hline Race/ethnicity & & & $<0.001$ \\
\hline Non-Hispanic white & $17,375(72.3)$ & $237,741(74.0)$ & \\
\hline Non-Hispanic black & $2,848(11.9)$ & $34,030(10.6)$ & \\
\hline Hispanic & $2,593(10.8)$ & $35,333(11.0)$ & \\
\hline Others & $1,217(5.1)$ & $14,034(4.5)$ & \\
\hline Primary health insurance & & & $<0.001$ \\
\hline Medicare & $20,089(81.4)$ & $233,472(70.3)$ & \\
\hline Medicaid & $1,817(7.4)$ & $36,878(11.1)$ & \\
\hline Private & $1,682(6.8)$ & $38,944(11.7)$ & \\
\hline Others & $1,093(4.4)$ & $22,698(6.9)$ & \\
\hline Median household income quartile & & & $<0.001$ \\
\hline 1 (lowest) & $7,216(29.7)$ & $103,211(31.9)$ & \\
\hline 2 & $6,230(25.6)$ & $89,605(27.7)$ & \\
\hline 3 & $5,931(24.4)$ & $76,312(23.6)$ & \\
\hline 4 (highest) & $4,927(20.3)$ & $54,794(16.9)$ & \\
\hline Patient residence & & & $<0.001$ \\
\hline Metropolitan & $22,529(90.8)$ & $288,858(87.0)$ & \\
\hline Non-metropolitan & $2,304(9.2)$ & $43,299(13.0)$ & \\
\hline \multicolumn{4}{|l|}{ Selected comorbidities* } \\
\hline Congestive heart failure & $11,326(45.6)$ & $78,120(23.5)$ & $<0.001$ \\
\hline Depression & $3,348(13.5)$ & $52,482(15.8)$ & $<0.001$ \\
\hline Diabetes & $10,415(41.9)$ & $93,904(28.3)$ & $<0.001$ \\
\hline Hypertension & $20,125(81.0)$ & $219,396(66.1)$ & $<0.001$ \\
\hline Obesity & $5,048(20.3)$ & $50,795(15.3)$ & $<0.001$ \\
\hline Peripheral artery disease & 2,967 (11.9) & $24,961(7.5 \%)$ & $<0.001$ \\
\hline Chronic kidney disease & $13,481(54.3)$ & $34,518(10.4)$ & $<0.001$ \\
\hline Hospital length-of-stay & & & $<0.001$ \\
\hline$<3$ days & $3,599(14.5)$ & $97,877(29.5)$ & \\
\hline 3-4 days & $7,223(29.1)$ & $117,624(35.4)$ & \\
\hline 5-6 days & $5,407(21.8)$ & $60,523(18.2)$ & \\
\hline$\geq 7$ days & $8,604(34.6)$ & $56,133(16.9)$ & \\
\hline
\end{tabular}




\begin{tabular}{lcc}
\hline Hospital state & \multicolumn{2}{c}{$<0.001$} \\
\hline Arkansas & $1,695(6.8)$ & $15,644(4.7)$ \\
\hline California & $4,561(18.4)$ & $63,913(19.2)$ \\
\hline Florida & $10,295(41.5)$ & $135,717(40.9)$ \\
\hline Iowa & $764(3.1)$ & $11,825(3.6)$ \\
\hline Nebraska & $536(2.2)$ & $7,252(2.2)$ \\
New York & $6,667(26.8)$ & $93,863(28.3)$ \\
\hline Utah & $315(1.3)$ & $3,943(1.2)$ \\
\hline
\end{tabular}

Abbreviations: AKI, acute kidney injury; IQR, interquartile range

Data are shown as n (\%) unless otherwise specified

* Selected from 29 Elixhauser comorbidity measures and arrhythmia

Table 2. Hazard ratio for all-cause readmission during 30-day periods after index hospitalization for acute exacerbation of chronic obstructive pulmonary disease, according to acute kidney injury, overall and stratified by age category and sex and chronic kidney disease 


\begin{tabular}{|c|c|c|c|c|c|c|c|}
\hline & \multicolumn{2}{|c|}{ 30-day readmission rate } & \multicolumn{2}{|c|}{$\begin{array}{l}\text { Unadjusted } \\
\text { model }\end{array}$} & \multicolumn{2}{|c|}{$\begin{array}{l}\text { Adjusted } \\
\text { model* }\end{array}$} & \multirow[b]{2}{*}{$\begin{array}{c}\text { P for } \\
\text { interaction }\end{array}$} \\
\hline & $\begin{array}{c}\text { AKI } \\
(\mathrm{n}=24,833) \\
\end{array}$ & $\begin{array}{c}\text { Non-AKI } \\
(\mathrm{n}=332,157)\end{array}$ & $\begin{array}{l}\text { HR } \\
(95 \% \\
\text { CI) }\end{array}$ & P-value & $\begin{array}{l}\text { HR } \\
(95 \% \\
\text { CI) }\end{array}$ & P-value & \\
\hline $\begin{array}{l}\text { Overall } \\
(\mathrm{n}=356,990)\end{array}$ & $22.4 \%$ & $15.8 \%$ & $\begin{array}{c}1.47 \\
(1.43- \\
1.51)\end{array}$ & $<0.001$ & $\begin{array}{c}1.07 \\
(1.04- \\
1.11)\end{array}$ & $<0.001$ & \\
\hline \multicolumn{8}{|l|}{ Age category } \\
\hline $\begin{array}{l}40-64 \quad \text { years } \\
(\mathrm{n}=122,362)\end{array}$ & $20.9 \%$ & $14.0 \%$ & $\begin{array}{c}1.52 \\
(1.43- \\
1.63)\end{array}$ & $<0.001$ & $\begin{array}{l}1.03 \\
(0.96- \\
1.10)\end{array}$ & 0.45 & \multirow[t]{2}{*}{0.13} \\
\hline $\begin{array}{l}\geq 65 \quad \text { years } \\
(\mathrm{n}=234,628)\end{array}$ & $22.7 \%$ & $16.8 \%$ & $\begin{array}{c}1.41 \\
(1.36- \\
1.45)\end{array}$ & $<0.001$ & $\begin{array}{c}1.09 \\
(1.05- \\
1.13)\end{array}$ & $<0.001$ & \\
\hline \multicolumn{8}{|l|}{ Sext } \\
\hline $\begin{array}{l}\text { Men } \\
(\mathrm{n}=149,333)\end{array}$ & $22.0 \%$ & $16.7 \%$ & $\begin{array}{l}1.36 \\
(1.30- \\
1.41)\end{array}$ & $<0.001$ & $\begin{array}{l}1.03 \\
(0.99- \\
1.08)\end{array}$ & 0.14 & \multirow[t]{2}{*}{0.07} \\
\hline $\begin{array}{l}\text { Women } \\
(\mathrm{n}=207,436)\end{array}$ & $22.7 \%$ & $15.2 \%$ & $\begin{array}{l}1.56 \\
(1.50- \\
1.62)\end{array}$ & $<0.001$ & $\begin{array}{l}1.12 \\
(1.07- \\
1.17)\end{array}$ & $<0.001$ & \\
\hline \multicolumn{8}{|l|}{$\begin{array}{l}\text { Chronic kidney } \\
\text { disease } \ddagger\end{array}$} \\
\hline $\begin{array}{l}\text { Chronic kidney } \\
\text { disease } \\
(\mathrm{n}=47,999)\end{array}$ & $27.7 \%$ & $24.2 \%$ & $\begin{array}{l}1.14 \\
(1.09- \\
1.18)\end{array}$ & $<0.001$ & $\begin{array}{l}1.03 \\
(0.99- \\
1.07)\end{array}$ & 0.24 & \multirow[t]{2}{*}{0.01} \\
\hline $\begin{array}{lr}\text { No } & \text { chronic } \\
\text { kidney } & \text { disease } \\
(\mathrm{n}=308,991)\end{array}$ & $22.3 \%$ & $16.8 \%$ & $\begin{array}{l}1.32 \\
(1.26- \\
1.38) \\
\end{array}$ & $<0.001$ & $\begin{array}{l}1.09 \\
(1.05- \\
1.15) \\
\end{array}$ & $<0.001$ & \\
\hline
\end{tabular}

Abbreviations: AKI, acute kidney injury; HR, hazard ratio; CI, confidence interval

* Cox proportional hazards model adjusting for age, sex, race/ethnicity, insurance status, estimated household income, residential status, hospital length-of-stay, hospital state, and Elixhauser comorbidity measures and arrhythmia with generalized estimating equations to account for patient clustering within hospitals

† 221 patients with missingness on sex data

¥ Chronic kidney disease was defined by the Elixhauser comorbidities

Table 3. Hazard ratio for all-cause readmission during 90-day periods after index hospitalization for acute exacerbation of chronic obstructive pulmonary disease, according to acute kidney injury, overall and stratified by age category and sex and chronic kidney disease 


\begin{tabular}{|c|c|c|c|c|c|c|c|}
\hline & \multicolumn{2}{|c|}{ 90-day Readmission rate } & \multicolumn{2}{|c|}{$\begin{array}{c}\text { Unadjusted } \\
\text { model }\end{array}$} & \multicolumn{2}{|c|}{$\begin{array}{c}\text { Adjusted } \\
\text { model* }\end{array}$} & \multirow[b]{2}{*}{$\begin{array}{c}\mathrm{P} \text { for } \\
\text { interaction }\end{array}$} \\
\hline & $\begin{array}{c}\text { AKI } \\
(n=24,833)\end{array}$ & $\begin{array}{c}\text { Non-AKI } \\
(\mathrm{n}=332,157)\end{array}$ & $\begin{array}{l}\mathrm{HR} \\
(95 \% \\
\mathrm{CI})\end{array}$ & P-value & $\begin{array}{l}\mathrm{HR} \\
(95 \% \\
\mathrm{CI})\end{array}$ & $\begin{array}{c}\mathrm{P}- \\
\text { value }\end{array}$ & \\
\hline $\begin{array}{l}\text { Overall } \\
(\mathrm{n}=356,990)\end{array}$ & $39.7 \%$ & $31.0 \%$ & $\begin{array}{l}1.35 \\
(1.32- \\
1.38)\end{array}$ & $<0.001$ & $\begin{array}{l}1.03 \\
(1.00- \\
1.05)\end{array}$ & 0.04 & \\
\hline \multicolumn{8}{|l|}{ Age category } \\
\hline $\begin{array}{c}40-64 \\
(n=122,362)\end{array}$ years & $37.6 \%$ & $27.8 \%$ & $\begin{array}{l}1.43 \\
(1.36- \\
1.50)\end{array}$ & $<0.001$ & $\begin{array}{l}1.00 \\
(0.95- \\
1.06)\end{array}$ & 0.86 & 0.10 \\
\hline$\underset{(n=234,628)}{\geq 65} \quad$ years & $40.2 \%$ & $32.8 \%$ & $\begin{array}{l}1.29 \\
(1.26- \\
1.32)\end{array}$ & $<0.001$ & $\begin{array}{l}1.03 \\
(1.00- \\
1.06)\end{array}$ & 0.03 & \\
\hline \multicolumn{8}{|l|}{ Sex $†$} \\
\hline Men $(n=149,333)$ & $38,9 \%$ & $32.2 \%$ & $\begin{array}{c}1.26 \\
(1.22- \\
1.29)\end{array}$ & $<0.001$ & $\begin{array}{l}0.99 \\
(0.96- \\
1.03)\end{array}$ & 0.59 & \multirow[t]{2}{*}{0.06} \\
\hline $\begin{array}{l}\text { Women } \\
(n=207,436)\end{array}$ & $40.5 \%$ & $30.2 \%$ & $\begin{array}{c}1.43 \\
(1.39- \\
1.48)\end{array}$ & $<0.001$ & $\begin{array}{c}1.06 \\
(1.02- \\
1.09)\end{array}$ & 0.001 & \\
\hline \multicolumn{8}{|l|}{$\begin{array}{l}\text { Chronic kidney } \\
\text { disease } \neq\end{array}$} \\
\hline $\begin{array}{l}\text { Chronic kidney } \\
\text { disease } \\
(\mathrm{n}=47,999)\end{array}$ & $43.0 \%$ & $40.9 \%$ & $\begin{array}{l}1.06 \\
(1.03- \\
1.09)\end{array}$ & 0.001 & $\begin{array}{l}0.98 \\
(0.95- \\
1.02)\end{array}$ & 0.21 & \multirow[t]{2}{*}{$<0.001$} \\
\hline $\begin{array}{l}\text { No chronic kidney } \\
\text { disease } \\
(\mathrm{n}=308,991)\end{array}$ & $35.7 \%$ & $29.9 \%$ & $\begin{array}{c}1.22 \\
(1.18- \\
1.26)\end{array}$ & $<0.001$ & $\begin{array}{l}1.04 \\
(1.00- \\
1.07)\end{array}$ & 0.04 & \\
\hline
\end{tabular}

Abbreviations: AKI, acute kidney injury; HR, hazard ratio; CI, confidence interval

* Cox proportional hazards model adjusting age, sex, race/ethnicity, insurance status, estimated household income, residential status, hospital length-of-stay, hospital state, and Elixhauser comorbidity measures and arrhythmia with generalized estimating equations to account for patient clustering within hospitals

† 221 patients with missingness on sex data

¥ Chronic kidney disease was defined by the Elixhauser comorbidities

Table 4. The ten most frequent principal diagnoses of 30-day readmissions in patient hospitalized for acute exacerbation of chronic obstructive pulmonary disease, stratified by acute kidney injury 


\begin{tabular}{lclc}
\hline \multicolumn{2}{c}{ Without AKI (n=50,984) } & \multicolumn{2}{c}{ With AKI (n=8,151) } \\
\hline \multicolumn{1}{c}{ Primary diagnosis* } & $\mathbf{n ~ ( \% )}$ & \multicolumn{1}{c}{ Primary diagnosis* } & $\mathbf{n}(\%)$ \\
\hline COPD and bronchiectasis & $12,954(25.4)$ & Septicemia & $1,176(14.4)$ \\
Pneumonia & $3,947(7.7)$ & Acute renal failure & $963(11.8)$ \\
Respiratory failure & $3,571(7.0)$ & COPD and bronchiectasis & $944(11.6)$ \\
\hline Asthma & $3,255(6.4)$ & Congestive heart failure & $713(8.8)$ \\
\hline Congestive heart failure & $3.019(5.9)$ & Respiratory failure & $623(7.6)$ \\
Septicemia & $1,806(3.5)$ & Pneumonia & $579(7.1)$ \\
Cardiac dysrhythmia & $1,395(2.7)$ & Asthma & $204(2.5)$ \\
\hline Nonspecific chest pain & $921(1.8)$ & Acute myocardial infarction & $166(2.0)$ \\
Aspiration pneumonitis & $683(1.3)$ & Nonspecific chest pain & $166(2.0)$ \\
Fluid and electrolyte disorders & $666(1.3)$ & Intestinal infection & $158(1.9)$ \\
\hline
\end{tabular}

*The primary diagnosis codes (>14,000 ICD-9-CM diagnosis codes) are consolidated into 285 mutually exclusive diagnostic categories by using the AHRQ-defined Clinical Classifications Software.

\section{Figures}

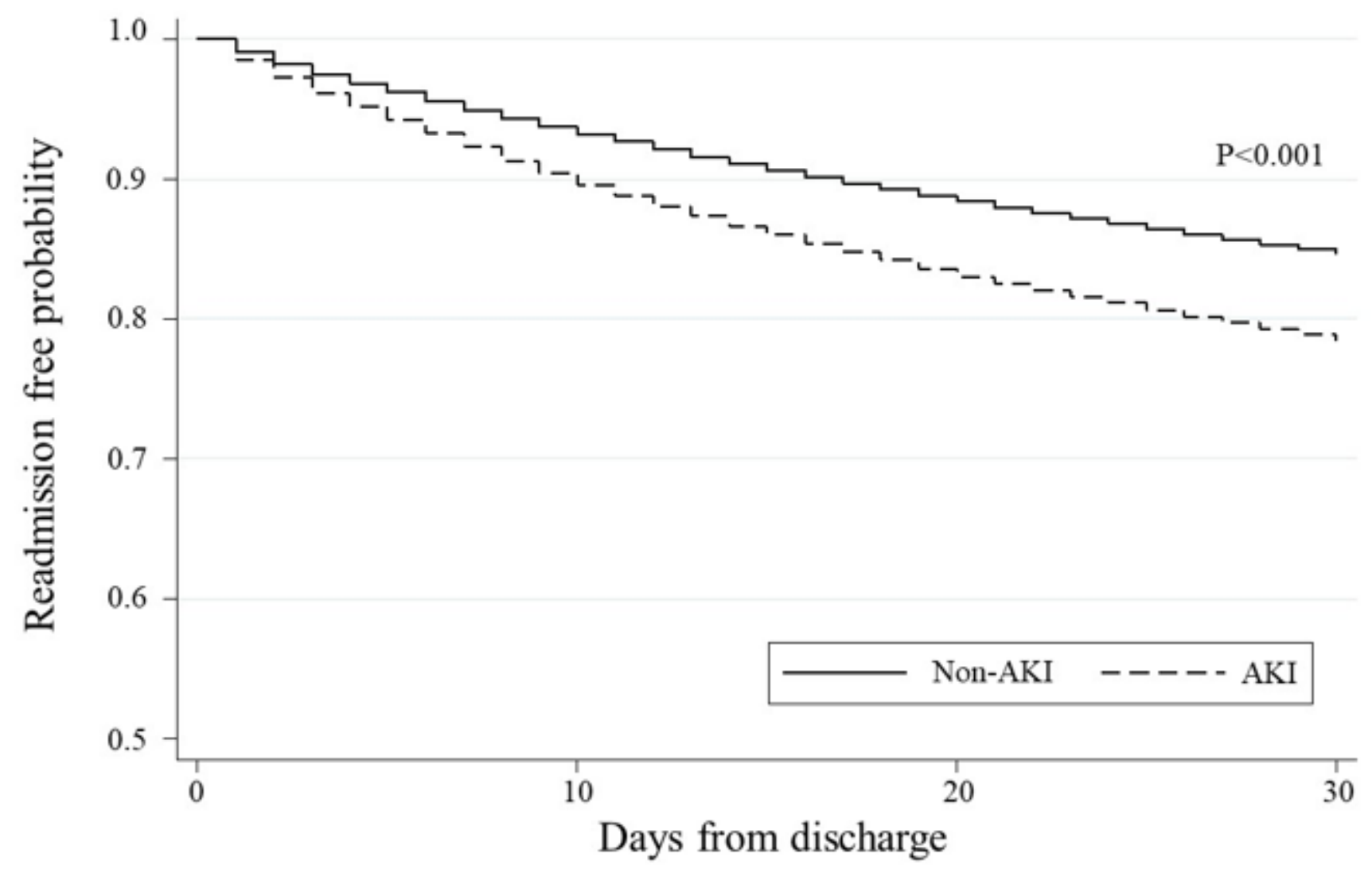

Figure 1

Kaplan-Meier survival estimates of all-cause readmission risk during 30-day period after the index hospitalization for acute exacerbation of chronic obstructive pulmonary disease Patients with acute 
kidney injury (AKI) had a significantly higher risk of all-cause readmission during 30-day period after the index hospitalization, compared to those without AKI (Plog-rank <0.001).

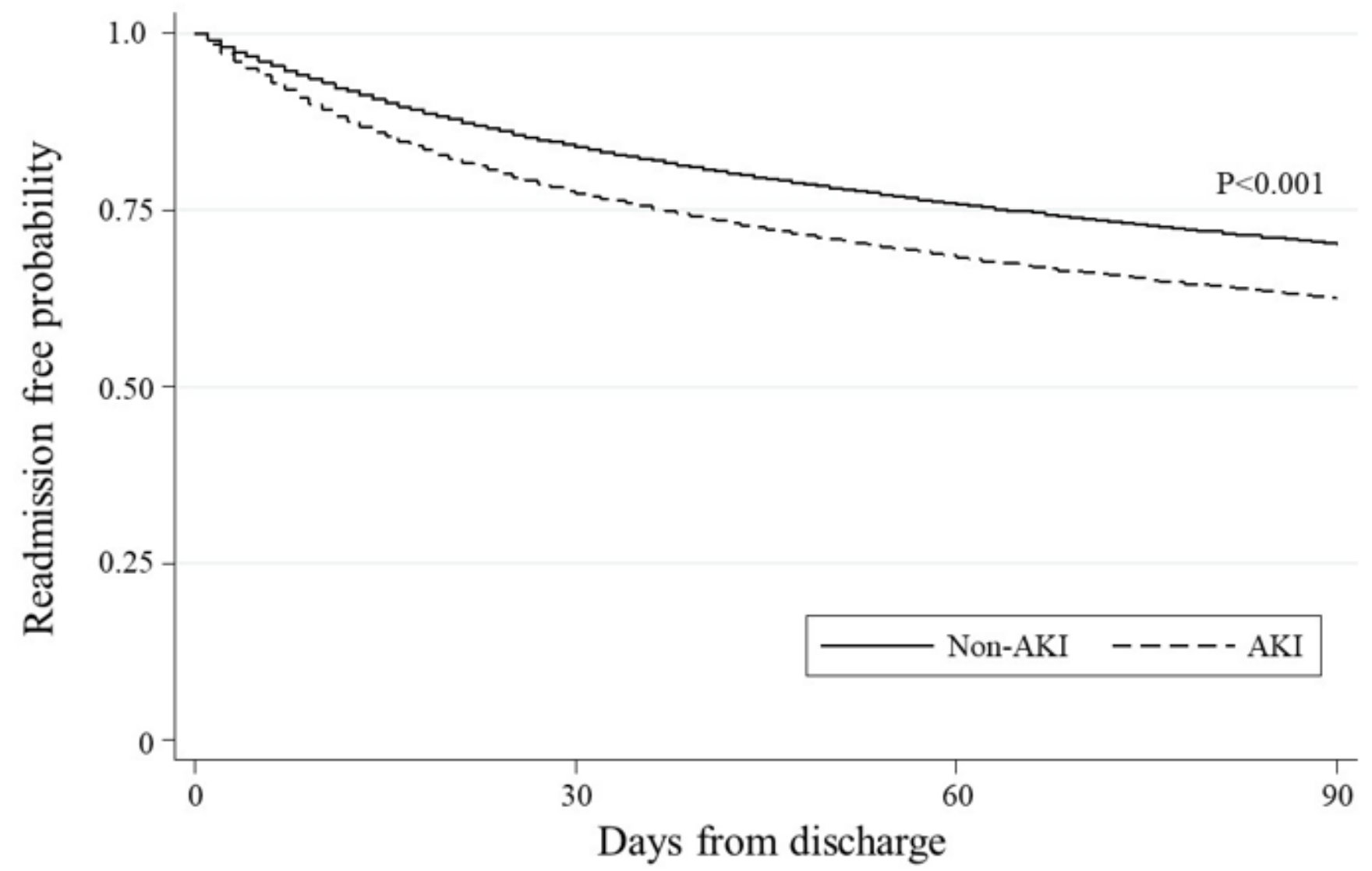

Figure 2

Kaplan-Meier survival estimates of all-cause readmission risk during 90-day period after the index hospitalization for acute exacerbation of chronic obstructive pulmonary disease Patients with acute kidney injury (AKI) had a significantly higher risk of all-cause readmission during 90 -day period after the index hospitalization, compared to those without AKI (Plog-rank <0.001).

\section{Supplementary Files}

This is a list of supplementary files associated with this preprint. Click to download.

- cleanedHirayamaSupplementalfigureBMCNephrolfinal.docx

- cleanedHirayamaSuptabBMCNephrolfinal.docx 